\title{
Prophylaxe
}

\section{Gehen Sie dazwischen!}

Speisereste, Bakterien und Zahnbeläge siedeln sich besonders schnell und geschützt in den Zahnzwischenräumen sowie an Brackets, Spangen und Brücken an. Zur professionellen Zahnreinigung hat miradent sein Prophylaxesortiment um die neue farbkodierte Interdentalbürste IProx L erweitert. Der verlängerte L-förmige Griff und der abgewinkelte Kopf $\left(60^{\circ}\right.$-Winkel) ermöglichen eine leichtere

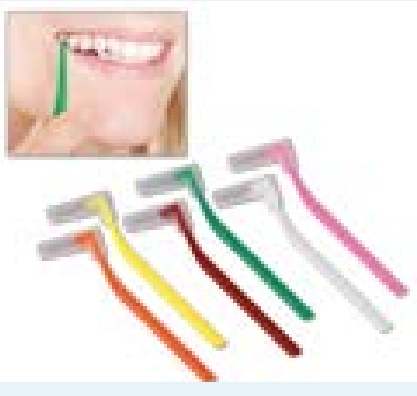

Handhabung und hygienischeren Zugang in den Mundinnenraum. Die Bürsten sind in 6 unterschiedlichen Stärken (xx-fine bis large) erhältlich. Somit findet sich für jeden Zahnzwischenraum die exakte, passende Größe. Die Bürste eignet sich perfekt zur Kontrolle und zur finalen Reinigung der Interdentalräume nach der Durchführung einer PZR oder UPT. Auch für die häusliche Mundpflege eignet sich die Interdentalbürste ideal, denn sie wird durch eine luftdurchlässige, hygienische Kappe geschützt. Die Borsten und der durch Kunststoff ummantelte Draht werden auf diese Weise vor Verunreinigung oder Schaden geschützt..

Nach einer Pressemitteilung der

Hager \& Werken GmbH \& Co. KG, Duisburg 